\title{
RESEARCH ON TRAINING SYSTEM OF PRODUCT DESIGN MAJOR BASED ON NEW DESIGN REQUIREMENTS
}

\begin{abstract}
Shi BX*
Beijing Institute of Technology Zhuhai, China

Abstract: With the advent of the industry 4 and the Internet plus era, the industrial structure of various industries is also constantly upgrading. As a major closely integrated with the industry, the characteristics of product design are also changing. But at present, some colleges still use the previous student training system, not keeping up with the pace of the development of the times, nor adapting to the social demand for design talents. As teachers engaged in design education, the author has the responsibility to re-examine the new needs of various industries for design, reasonably reform the student training system, and improve the applicability of the training system. Through understanding the changes of the times' needs and qualitative analysis of the latest requirements of current enterprises for designers, the author deeply analyzes the existing training system of product design specialty, and from the perspective of system, reestablishes the ability requirements and knowledge requirements of product design specialty through questionnaire survey, and divides the training system into several ability modules and knowledge modules, and determine the ability and knowledge to be cultivated in each stage of the University. The goal of the new student training system is very clear, the key ability and knowledge have been strengthened, and the curriculum has also been improved.
\end{abstract}

Keywords: demand, product design, modular

\section{New design requirements along with the times}

Since the beginning of the $21^{\text {st }}$ century, society has undergone many major changes. The arrival of industry 4.0, the proposal of "Made in China 2025" and other national strategies indicate that social change is gradually deepening. General Secretary Xi Jinping (2018) put forward at the APEC summit that the new scientific and technological revolution and industrial transformation will have a profound impact on people's production, lifestyle and values. In the face of the emergence of Internet, big data, artificial intelligence and other technologies, university education will not be able to provide new power for industrial upgrading without reform. With the transformation of society and industry, the requirement of design education is higher and higher. It is mainly reflected in the following aspects:

\section{Industry 4.0 and Made in China 2025}

Since it was officially launched at Hanover Industrial Expo in April 2013, industry 4.0 has rapidly become another label of Germany, and triggered a new round of industrial transformation competition in the world. Industry 4.0 in Germany refers to the use of cyber physical system (CPS) to digitize and intelligentize the supply, manufacturing and sales information in production, and finally to achieve fast, effective and personalized product supply. 
In May 2015, the State Council issued "Made in China 2025", which made a comprehensive deployment from the national strategic level to promote the transformation and upgrading of manufacturing industry and enhance the global competitiveness of China's manufacturing industry. The cooperation between "Made in China 2025" and "Industry 4.0" of Germany officially started.

With the advent of industry 4.0, designers should not only complete the design work, but also go deep into the industrial chain, understand the manufacturing end and sales end, and infiltrate these comprehensive factors into the design process, so as to make the design works meet the requirements of the times. In addition, many traditional products are gradually turning to intelligent, and there are all kinds of virtual products. The emergence of the Internet of things also leads the horizontal development of product design, which requires designers to consider a single product in the whole IOT system in the design process and make a systematic layout.

At the same time, "Made in China 2025" makes the structure of manufacturing industry develop towards resource saving, makes the limited social resources be effectively utilized, and makes the manufacturing industry have higher added value and function, creating a new form of human survival and development (Zhang Lu, 2021). Under the guiding ideology of Made in China 2025, product design is not only based on the traditional function and modeling competition, but also more reflected in the competition of materials and processing. It requires that the materials to be more economical and environmentally friendly. Besides, it increases the sense of experience and added value of the product through deep processing, complex processing and material technology. This requires the designer to have a good understanding of the manufacturing end and material technology and can apply the relevant knowledge to the design practice, in order to design products that meet the requirements of the times. This is also in line with the requirements of industry 4.0.

\section{New engineering}

The idea of new engineering is proposed to actively respond to a new round of scientific and technological revolution and industrial change and support a series of national strategies such as service innovation driven development and "Made in China 2025". On April 8, 2017, the Ministry of Education held a seminar on new engineering construction in Tianjin University to discuss how to cultivate diversified and innovative outstanding engineering and technological talents, so as to provide intellectual and talent support for China's industrial development and international competition. Some points are mentioned (Action line of "new engineering" construction, 2017):

(1) We should strengthen the research on the demand of industrial development for engineering science and technology talents and do a good job in incremental optimization and stock adjustment.

(2) We should implement the concept of student-centered, widen students' choice space, facilitate students' interdisciplinary and inter school learning, enhance the interaction between teachers and students, reform teaching methods and assessment methods, and form a learner centered engineering education mode.

(3) Gather the advantageous resources of industry departments, scientific research institutes and enterprises, improve the collaborative education mode of combining science and education, integrating production and learning, and school enterprise cooperation, and build a shared collaborative education practice platform integrating education, training, and R \& D. 
The above suggestions have a certain reference value for the composition of the training system of product design major. Through extensive investigation and research, we can set the training objectives from the needs of industry and enterprise development, take students as the center, open more interdisciplinary courses, widen students' choice space, and form a learner centered education mode. At the same time, through the way of school enterprise cooperation and the integration of production and learning, the collaborative education practice platform is constructed.

\section{New requirements of "thick foundation and wide caliber"}

"Thick foundation, wide caliber" means that in the process of professional training, we should pay attention to the cultivation of profound and comprehensive basic quality and skills needed for future employment, and then carry out targeted professional training, so that students can be multidirectional and flexible in the process of employment. Hou Peiyong (1997) pointed out that "the socalled 'thick foundation and wide caliber' means that talents are required to have a solid basic theoretical knowledge system and a wide professional direction". This is not a new term, but in the new era, it should be given more connotation. In today's job-hunting, the competition is more and more fierce, and the knowledge required for the job is more and more extensive. A considerable number of graduates are forced to transfer to other related majors for employment. The emergence of this situation requires students to have a solid foundation of professional knowledge, and to have a certain span of professional knowledge to understand and master, in order to truly achieve "thick foundation, wide caliber", so that graduates can have more chances for a job, and can quickly adapt to different position, through re-learning, to meet all the skills requirements of the position.

\section{Analysis of the key points of the training system based on the new demand}

Facing the new design needs brought by the new era background, many colleges and universities begin to pay attention to the two platforms of curriculum teaching and practice teaching in the process of cultivating students. The major of product design belongs to the category of art in the subject classification. The students of local undergraduate colleges are mainly art students, and the foundation of science and engineering is relatively weak. Product design inevitably involves the mechanics, materials, mechanism, and structure of products, especially in the background of industry 4.0 and "new engineering", but in many colleges and universities, it has not been paid high attention to the existing curriculum system of product design major in the university stage. Meanwhile, colleges and universities are actively exploring new models and methods of practical teaching, but they cannot ensure the close connection between social needs and talent training. Most of the graduates are trained by local colleges and universities which cannot keep up with the pace of enterprise development, and the professional teaching content and enterprise skills cannot be well connected (Lu Guangpu and Zhang Lu, 2020).

Qian Feng and Zhang Jun (2016) also believe that most of the local colleges and universities in China have the following problems in the cultivation of product design professionals: first, the training objectives of local colleges and universities are general and the differences are not enough; Secondly, the supply and demand relationship between local universities and enterprises is not coordinated; Thirdly, practical teaching cannot be fully implemented and fulfilled; Fourth, there is a lack of a reasonable mechanism for the construction of teachers. 
Combined with the background of the new era and the existing problems of product design major, through the field investigation, understanding and analyzing the existing student training programs of product design major in brother colleges, and also conductsing in-depth interviews with enterprise personnel in Guangdong, Hong Kong and Macao region, the ability requirements and knowledge requirements of product design major through qualitative analysis are summarized. Finally, through questionnaire survey and quantitative analysis, the proportion of these abilities and knowledge requirements is obtained, so as to establish the basic framework of the student training system of product design major in Zhuhai College of Beijing University of technology, and lay the foundation for the construction of the whole system and the setting of specific courses.

Ten professional teachers of product design in Beijing Institute of technology Zhuhai have visited Zhejiang University, Beijing University of technology, Zhuhai branch of Beijing Normal University, Dalian University for nationalities, Ningbo Institute of engineering and other universities to learn about the current professional training system of product design. And through the face-to-face or online interviews with previous alumni, we can understand the skills needs for this major, especially the needs of enterprises in Guangdong, Hong Kong and Macao. Finally, the ability requirements and knowledge requirements of students in product design major are summarized. Through qualitative analysis, 9 ability quality requirements and 10 knowledge requirements are summed up. Then, through questionnaire survey, 100 questionnaires were distributed to past graduates, teachers of related majors in Colleges and universities, principals, and employees of design enterprises to investigate their views on product design professional ability and knowledge:

\section{Requirements on Ability and Knowledge}

\section{Figure 1}

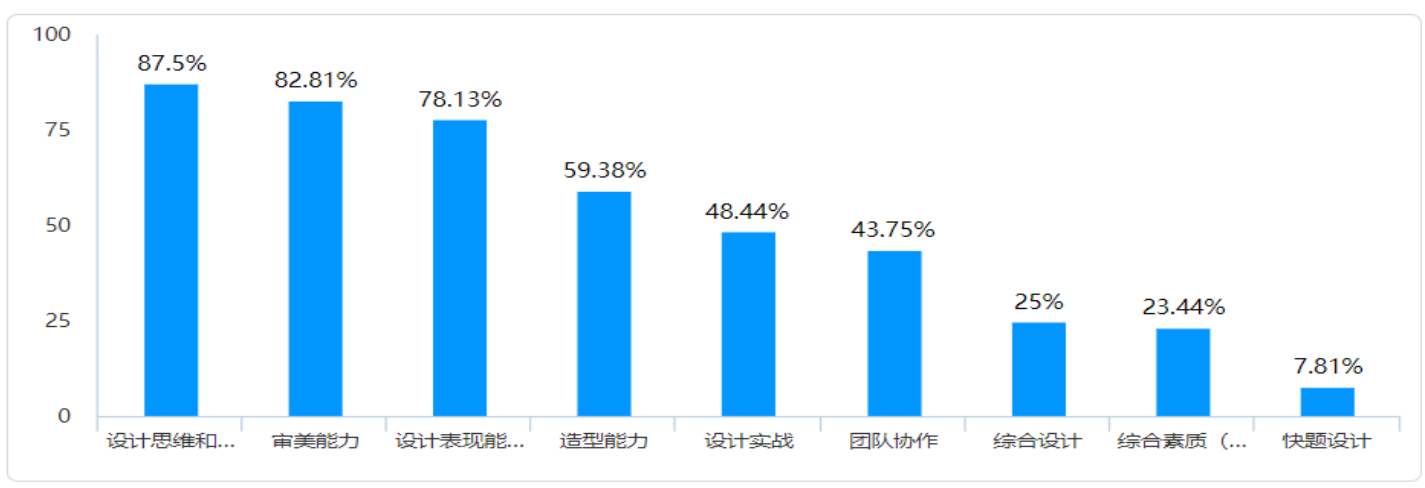

In terms of ability requirements, total 9 items are listed, a) design thinking and design expression, b) modeling ability, c) aesthetic ability, d) design performing ability (hand drawing, model, software, etc.), e) comprehensive design ability, f) fast topic design ability, g) team cooperation ability, h) comprehensive quality (Quality Development), i) design practical ability. According to the analysis results of the questionnaire survey, top five are: Design thinking and expression (87.5\%), Aesthetic ability (82.81\%), Design performance ability (78.13\%), Modeling ability (59.38\%), Design practice (48.44\%). As shown in Figure 1. 
Figure 2

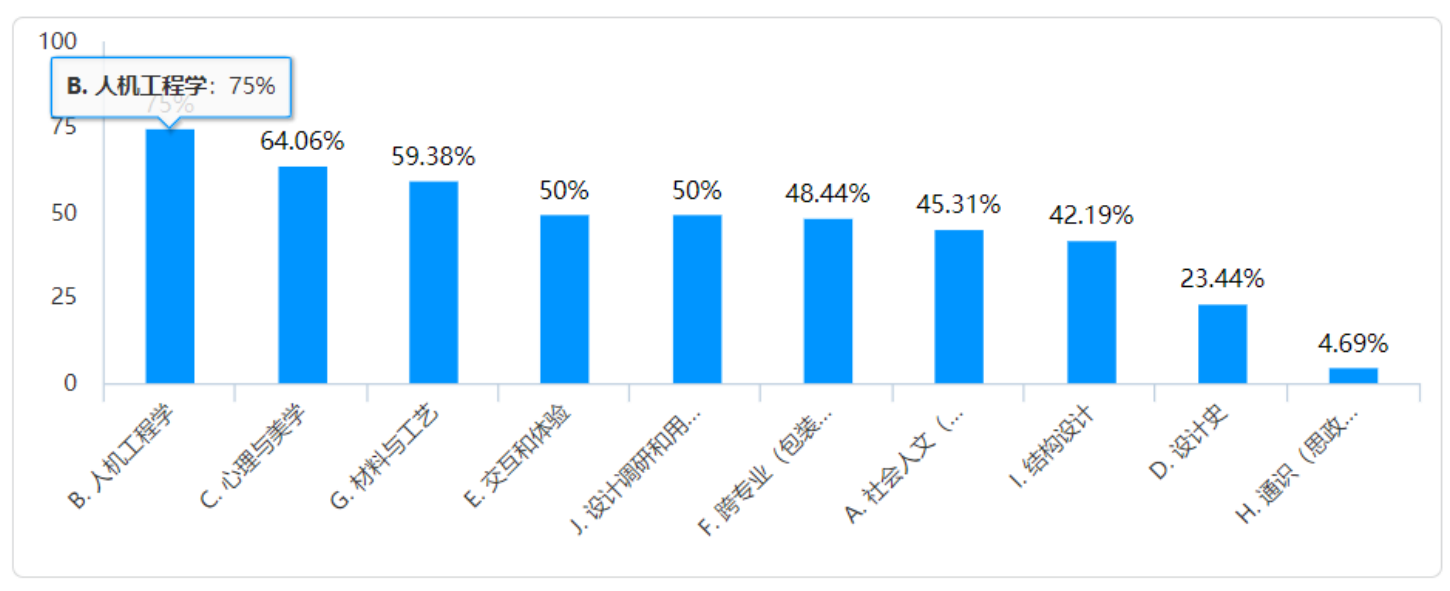

Knowledge Requirements, total 10 items: a) social humanities (society, culture, human geography, etc.), b) ergonomics, c) psychology and aesthetics, d) design history, e) interaction and user experience, f) interdisciplinary (packaging, brand, clothing and fabrics, interior and exhibition, digital media, information and computer technology, machinery, bioengineering, marketing, etc.), g) materials and technology, etc. h) General Education (ideological and political, social science, natural science, English, sports, etc.), h) structural design, i) Design research and user research. The top six are: Ergonomics (75\%), Psychology and aesthetics (64.06\%), materials and Technology (59.38\%), Interaction and experience (50\%), Design research and user research (50\%), Interdisciplinary (48.44\%). As shown in Figure 2.

\section{Figure 3}

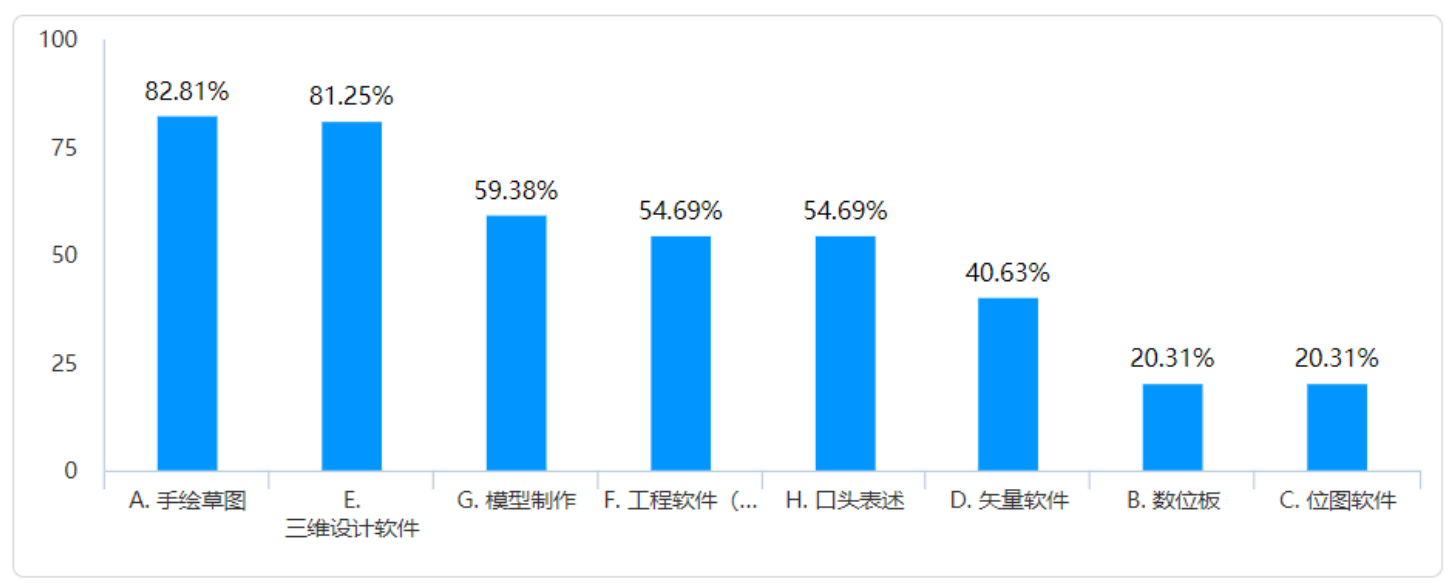

Design Performance ability, I listed 8 items, among which the top five were: Hand drawn sketches (82.81\%), 3D design software (81.25\%), Model making (59.38\%), Engineering software (54.69\%), Oral expression (54.69\%). As shown in Figure 3. 
Figure 4

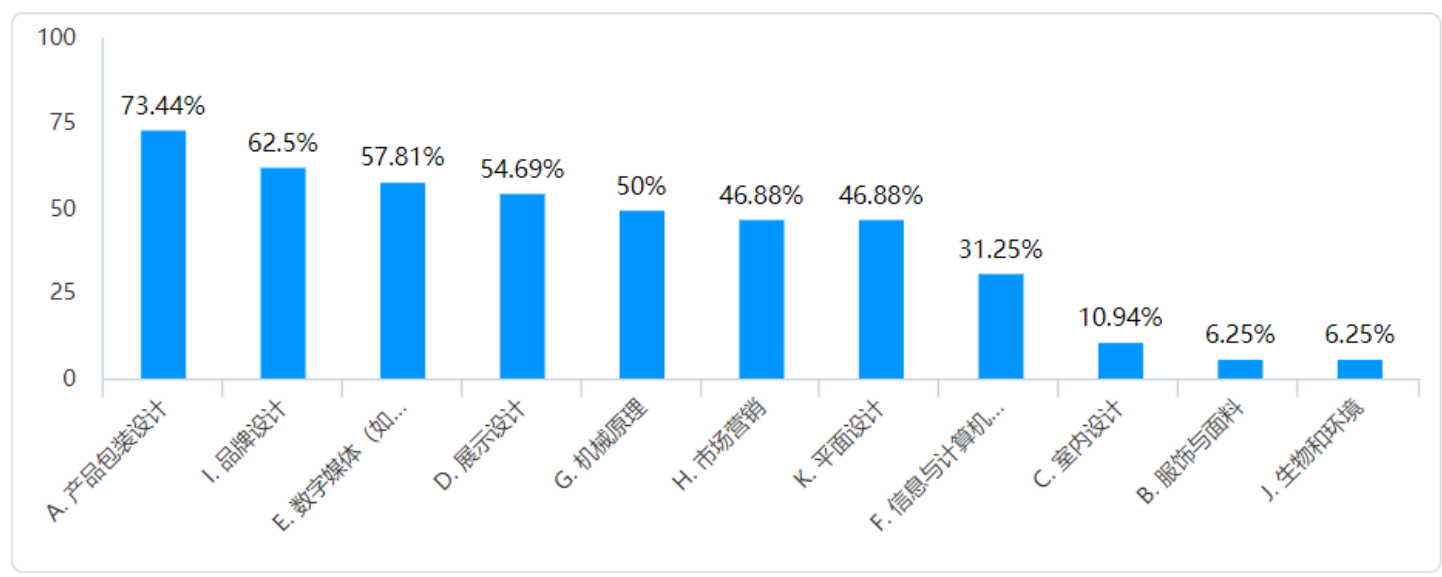

Interdisciplinary Knowledge, 11 items were listed, among of which the top six were Product packaging design (73.44\%), Brand design (62.5\%), Digital media (57.81\%), Display design (54.69\%), Mechanical principle (50\%), Marketing and graphic design (50\%). As shown in Figure 4.

Figure 5

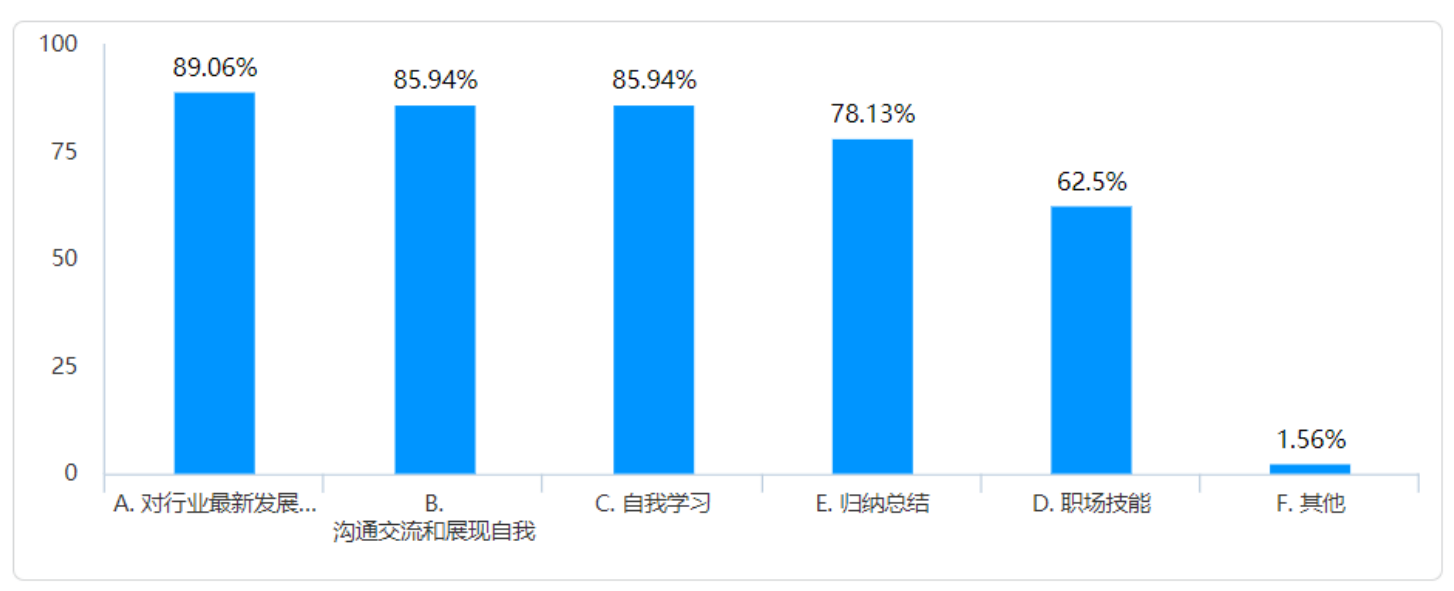

There are 6 comprehensive quality skills listed, and the proportion of selection is relatively close. The top four are: Understanding and mastering the latest development trend of the industry $(89.06 \%)$, Communication and self-presentation (85.94\%), Self-learning (85.94\%) and Induction (78.13\%). As shown in Figure 5.

To sum up, in the four-year training plan of product design major, the ability of design thinking and expression, aesthetic ability and design performance should be focused on, and the knowledge of ergonomics, psychology and aesthetics, materials and technology should be firmly mastered. On this basis, the modeling ability and design practical ability should be improved, and the interdisciplinary courses should be adopted, Master the knowledge of interaction and experience, product packaging design, brand design, digital media design, display design and mechanical principle. In the aspect of design performance, we should focus on the ability of hand drawing sketch and 3D design software, followed by the ability of model making. 


\section{Ability and knowledge training at different stages}

Though questionnaire, I understand what abilities and knowledge should be cultivated in each year from freshman to senior.

Figure 6

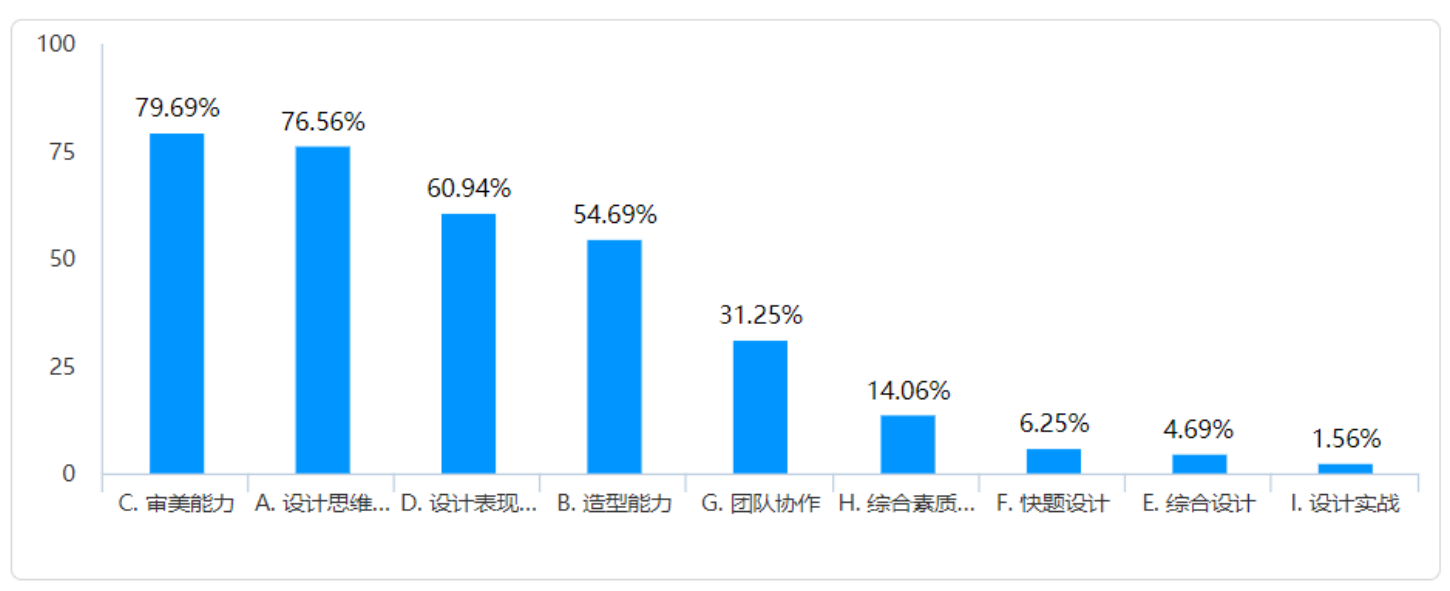

Figure 7

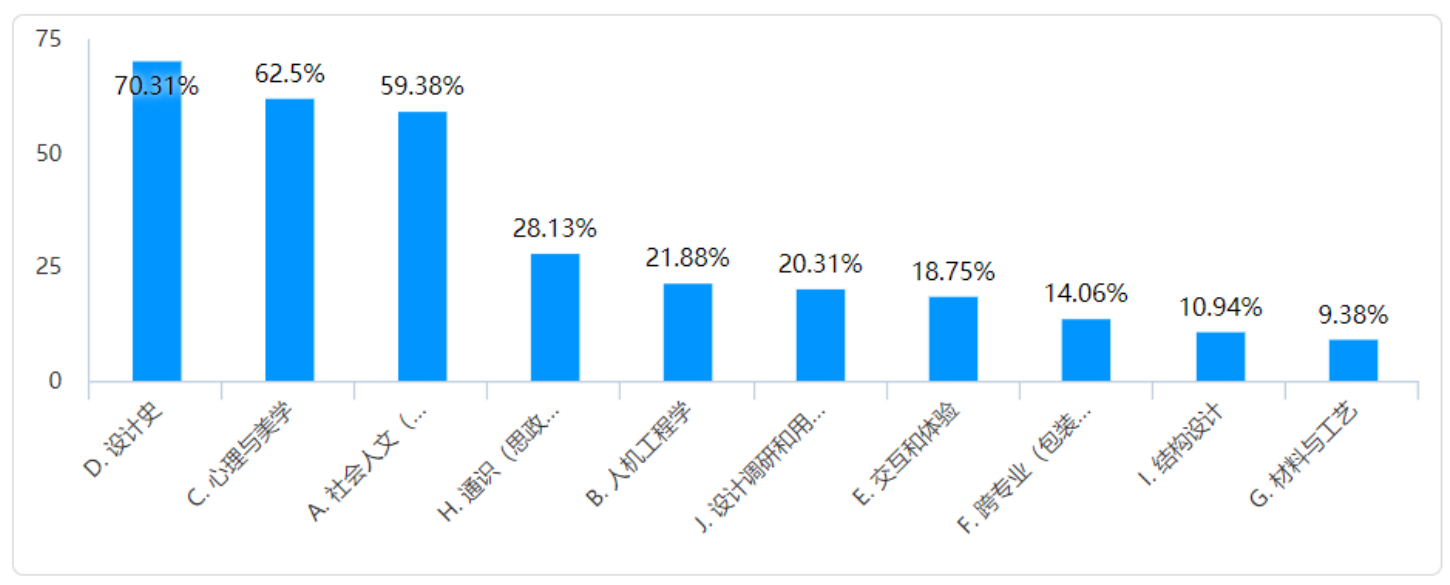

For freshmen, top four abilities they need to cultivate are: aesthetic ability (79.69\%), design thinking and expression ability (76.56\%), design expression ability (60.94\%), modeling ability $(54.69 \%)$, as shown in Figure 6. The top four knowledge that freshmen need to acquire are design history (70.31\%), psychology and aesthetics (62.5\%), social humanities (59.38\%) and general knowledge (28.13), as shown in Figure 7. 
Figure 8

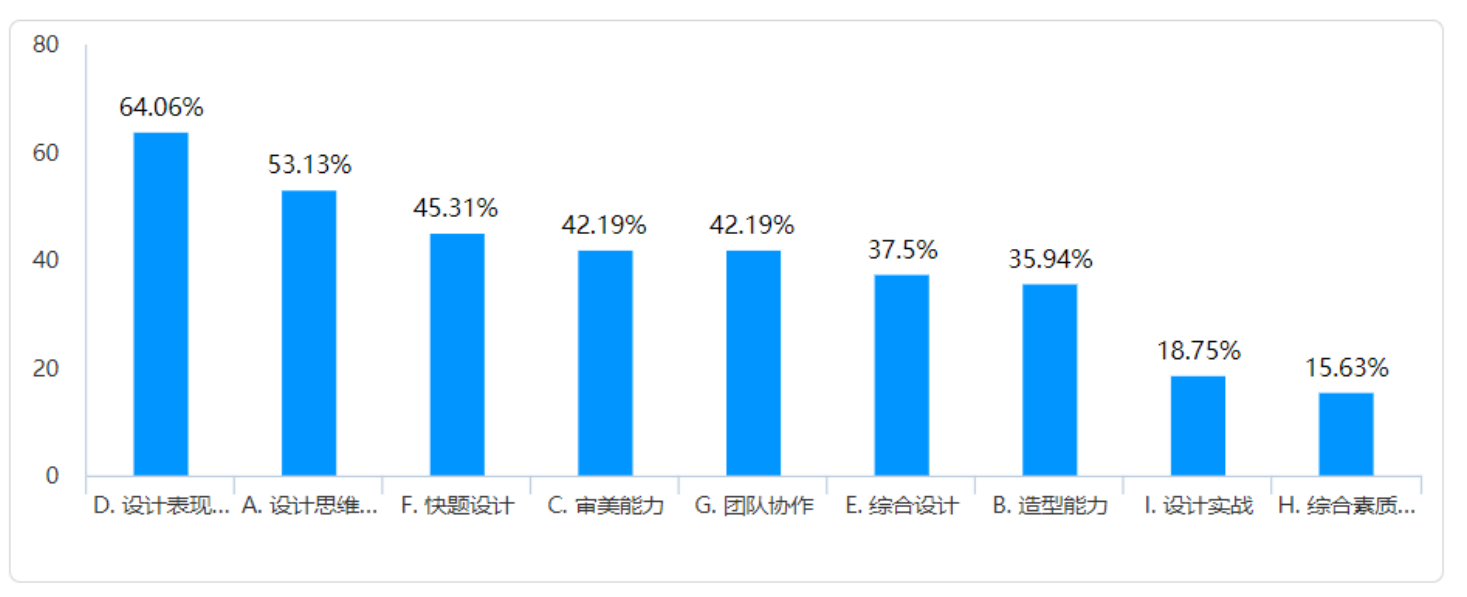

Figure 9

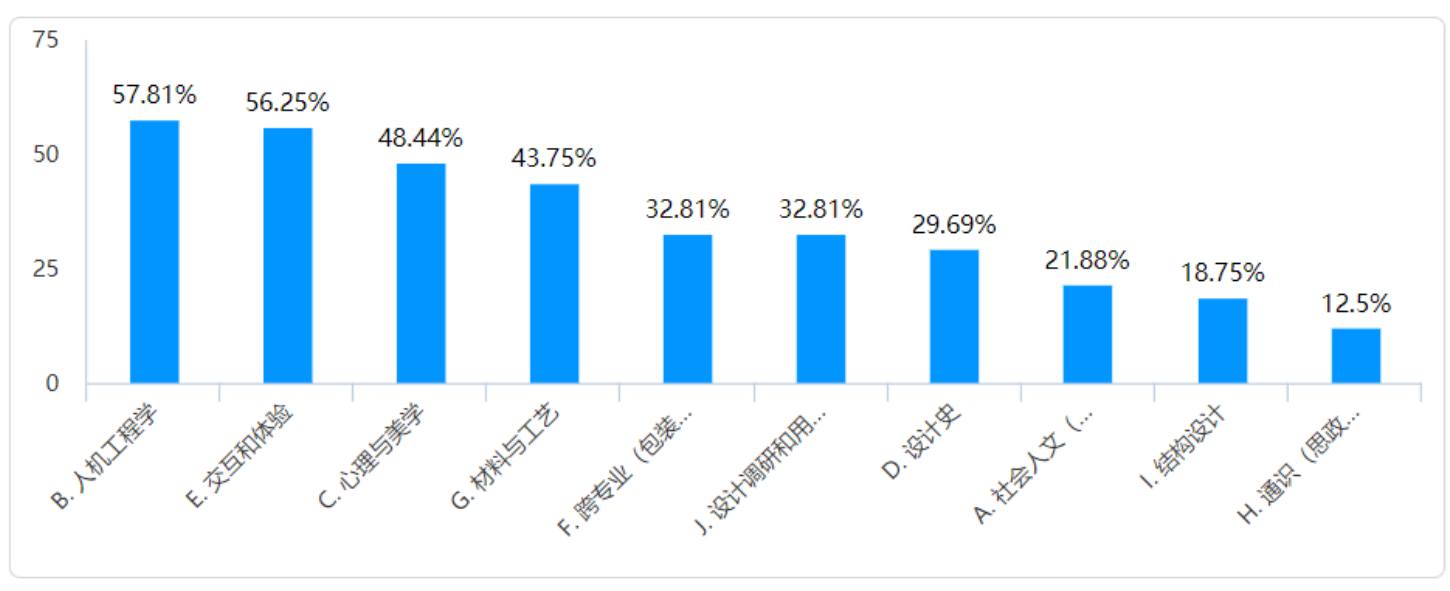

For sophomores, the top five abilities that sophomores need to cultivate are: design expression ability (64.06\%), design thinking and expression (53.13\%), fast question design (45.31\%), aesthetic ability (42.19\%), and teamwork (42.19\%), as shown in Figure 8. The top five knowledge that sophomores need to acquire are: Ergonomics $(57.81 \%)$, interaction and experience $(56.25 \%)$, psychology and aesthetics (48.44\%), materials and Technology (43.75\%), and interdisciplinary (32.81\%), as shown in Figure 9. 
Figure 10

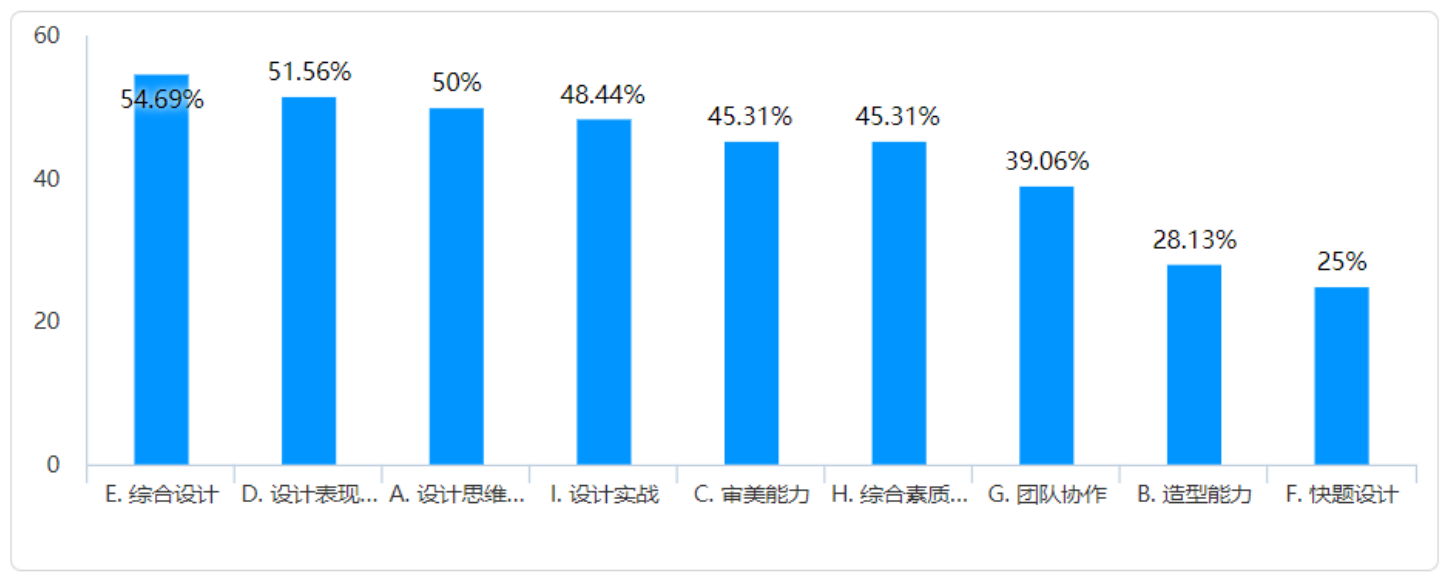

Figure 11

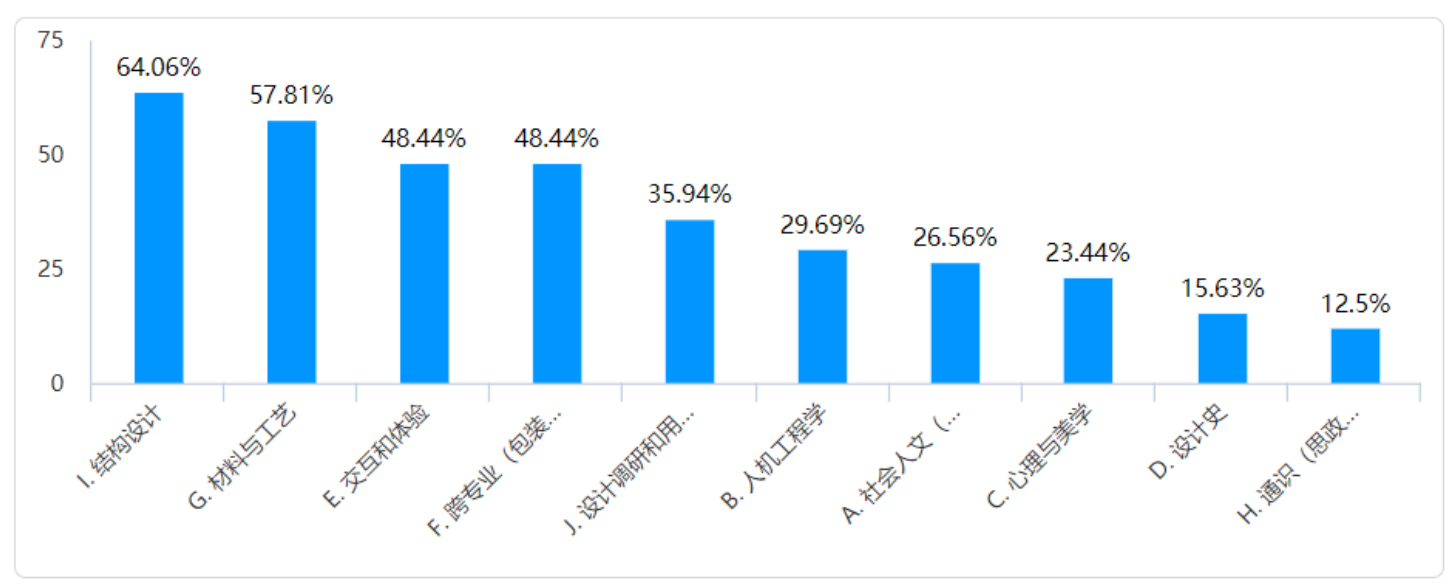

The top five abilities needed to be cultivated in the third year of university are: comprehensive design (54.69\%), design expression ability (51.56\%), design thinking and expression (50\%), design practice (48.44\%), aesthetic ability and comprehensive quality (45.31\%), as shown in Figure 10. The top five knowledge for the third year students are: structural design (64.06\%), materials and Technology (57.81\%), interaction and experience (48.44\%), interdisciplinary (48.44\%), design research and User Research (35.94\%). As shown in Figure 11. 
Figure 12

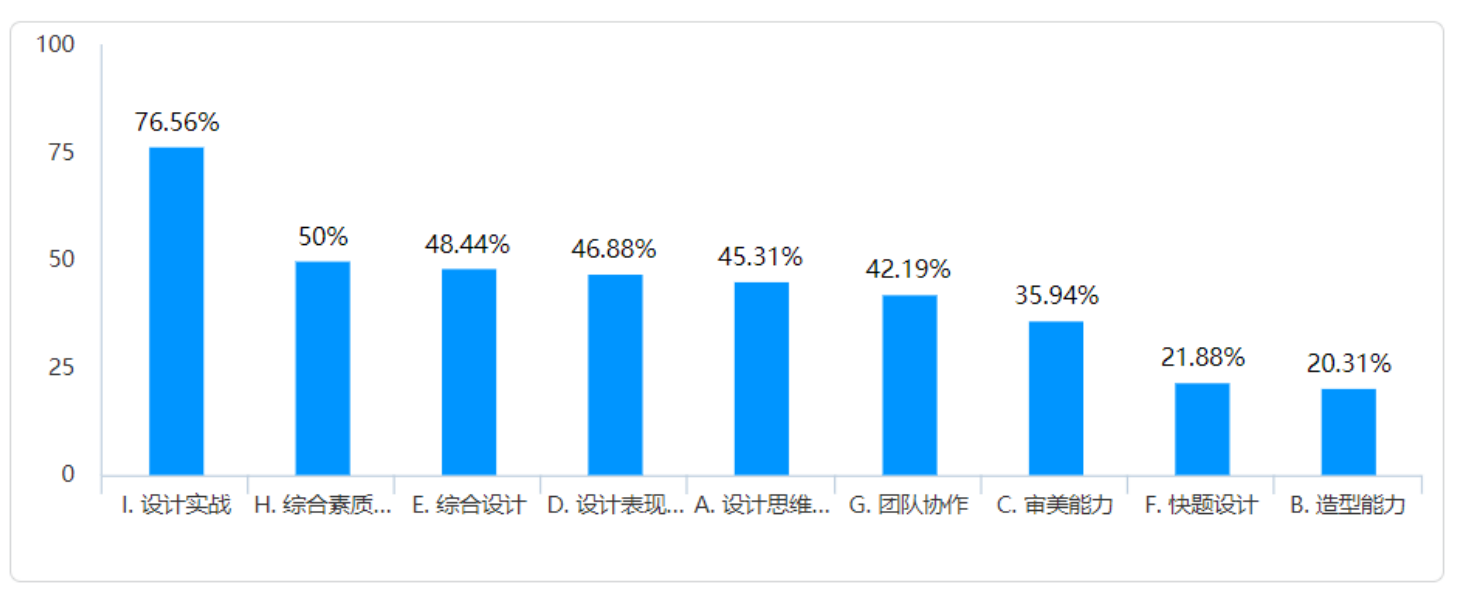

Figure 13

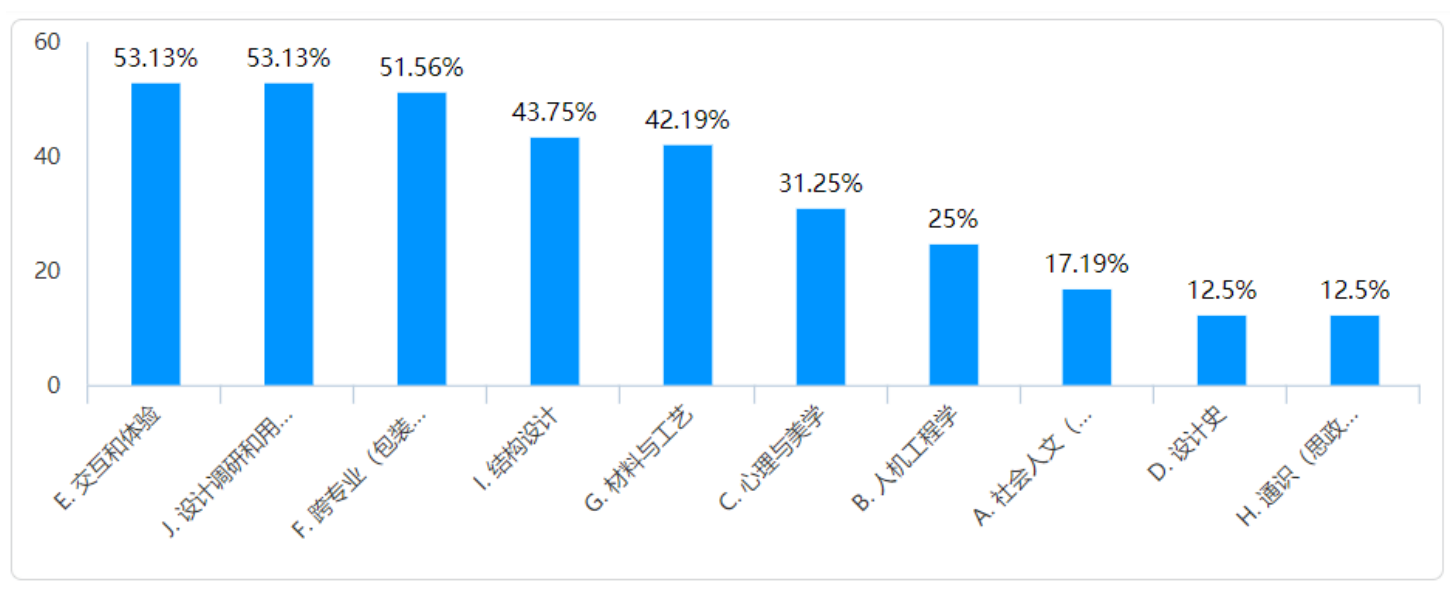

The top five abilities needed to be cultivated in the fourth year of university are: Design Practice (76.56\%), comprehensive quality (50\%), comprehensive design (48.44\%), design performance ability (46.88\%), design thinking and expression (45.31\%), as shown in Figure 12. The top five knowledge needed to be acquired in the fourth year of university are interaction and experience (53.13\%), design research and User Research (53.13\%), interdisciplinary (51.56\%), structural design (43.75\%), materials and Technology (42.19\%). As shown in Figure 13.

To sum up, in the four years of University, the tasks of ability and knowledge training should be reasonably allocated at different stages, and the corresponding credits should be reasonably set according to the different weights. On the other hand, the training at each stage shall overlap, so there will be the same ability and knowledge trainings in different stages. At this time, we should allocate credits reasonably in different stages according to the specific weight, so as to adapt to local conditions. 


\section{Auxiliary training means}

Figure 14

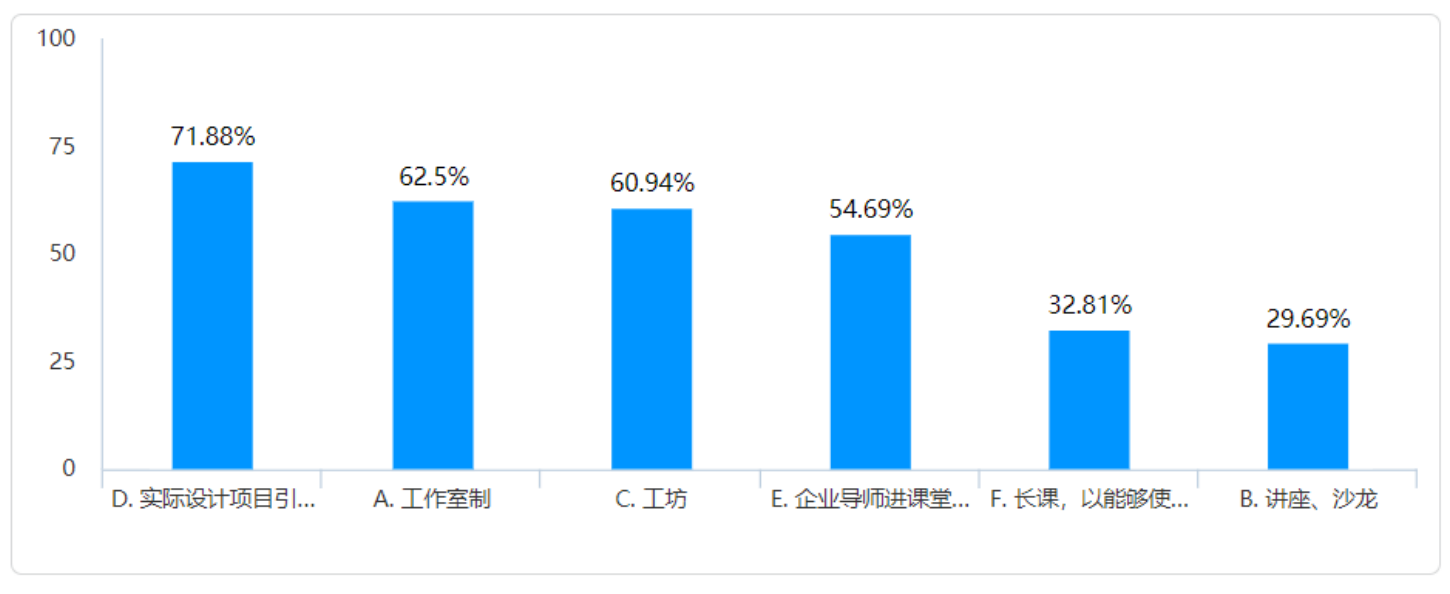

In addition to the traditional teaching ways, I listed several forms of auxiliary trainings, hoping to cultivate students' practical ability and system design ability. There are total 6 items listed, among of which the top 4 items are: Actual design projects entering the classroom (71.88\%), Studio system (62.5\%), Workshops (60.94\%), and Enterprise mentors entering the classroom to jointly complete design projects (54.69\%). As shown in Figure 14.

These auxiliary training methods are not only an important supplement to the normal classroom, but also an important means to cultivate students' practical ability. In order to meet the needs of design in the new era and keep up with the pace of enterprise development, these training methods are indispensable and one of the important ways to ensure the close connection between social needs and talent training.

\section{build product design professional training system framework according to the composition of the main points}

According to the results of above researches and analysis, the training system of product design specialty can be roughly divided into four core competence modules and four core knowledge modules. The four core competence modules are "design thinking and expression ability module", "aesthetic and modeling ability module", "design performance ability module" and "design combat ability module". The four core knowledge modules are "Ergonomics + interaction and experience", "design psychology and aesthetics", "materials and technology", "design research and user research". These modules will be interspersed in different stages of the four-year university, according to the patterns of students' learning and internal cognition.

There are 160 credits in the current training system of product design major in Zhuhai College of Beijing University of technology. According to the above quantitative analysis results, this paper will preliminarily allocate the credit proportion of each major module. According to the 9 ability requirements and 10 knowledge requirements summarized before, and the question and option setting in the questionnaire, assuming that the total credit is $\mathrm{F}$, the credit that a certain ability or knowledge should be allocated is $\mathrm{K}$, the selection rate of a certain ability or knowledge in the corresponding topic is $\mathrm{C}$, and the maximum number of options limited by the topic is $\mathrm{Q}$, then the credit calculation 
formula of a certain ability or knowledge can be obtained as follows: $\mathrm{K}=\mathrm{F} \times \frac{9 \text { or } 10}{19} \times \mathrm{C} \div \mathrm{q}$

\section{Ability module credit allocation}

According to the above formula, the total credits of "design thinking and expression ability module" in four years is about 13. The ability module runs through each stage of four years in the questionnaire, so relevant ability training courses or contents should be added in each grade, so that students can be strengthened in this aspect.

The total credit of "aesthetic and modeling ability module" in four years is about 10, mainly concentrated in the freshman and sophomore stages. Therefore, in these two stages, we should focus on improving students' aesthetic ability and modeling ability, and in the third stage, further strengthen students' aesthetic ability.

The total credit of "design performance ability module" in the four years is about 12 . This ability module runs through each stage of the four years in the questionnaire. The credit of each part of the performance ability should be reasonably allocated according to the students' cognition and learning patterns. According to the results of further investigation and analysis in the questionnaire, the proportion of hand-painted sketch, 3D design software and model making ability is particularly prominent. The credits of these three parts should be appropriately increased, and other auxiliary means should be used to help students form a good habit of self-learning. On one hand, professional training should not be turned into performance skills training, On the other hand, students' performance skills should be improved through multi-dimensional ways. Specifically, in the freshman stage, the introduction of hand-painted sketch learning, sophomore stage to strengthen, junior stage to enhance; At the same time, in other professional courses at the same stage, we should emphasize the use of 3D design software, so that students can constantly review and self-study outside the software course; In the freshman stage, we can introduce the learning of model making. First, we can try simple and easy forming materials and make some manual models. In the sophomore stage, we can try some materials that need machine processing and make relatively accurate models. In the third stage, we can use CNC or 3D printing technology to make appearance models with simple structure. At the same time, in the process of other professional courses, students can also be required to make models, and these auxiliary methods can be used to strengthen students' ability of making models.

The total credit of "design practical ability module" in four years is about 8 credits, mainly concentrated in the junior and senior stages. In addition to the conventional courses, it can also continuously strengthen students' practical ability through the collaborative education platform integrating production, teaching and research, as well as auxiliary means such as design projects into courses, studio system, workshops, investigation and practice. Through the introduction of enterprise project into the classroom, on the one hand, it can improve students' project combat ability, on the other hand, it is also conducive to cultivate talents from the needs of enterprises and meet the new engineering students' ideas in talent training. 


\section{Knowledge module credit allocation}

According to the above formula, the total credits of "Ergonomics + interaction and experience" knowledge module in four years is about 10.5, mainly concentrated in the sophomore and junior stages. Ergonomics, as the highest proportion of knowledge training in the questionnaire survey, should be taken as the key content to increase credits, which can be divided into two semesters of sophomore, At the same time, combined with interactive and experiential courses, the two intersect and integrate with each other, so that students can constantly repeat and improve the relevant knowledge, and achieve a firm grasp of the degree.

The total credit of "design psychology and aesthetics" module in four years is about 11, mainly concentrated in the freshman and sophomore stages. It is the second most important knowledge item in the questionnaire results and occupies a very important position. It should be cultivated together with aesthetic ability. In the freshman stage, we should cultivate the knowledge of aesthetics, and in the sophomore stage, we should focus on the knowledge of design psychology.

The total credits of "materials and technology" module in the four years is about 10, mainly concentrated in the sophomore and junior stage, and still occupies an important position in the senior stage. It should be combined with the training process of model making ability to gradually deepen the knowledge of materials and technology. We can introduce the course of materials and technology in the sophomore stage, combine the model making course in the same stage, and apply the knowledge of materials and technology to the practice of model making, the two complement each other.

The total credit of "design research and user research" module in four years is about 8.5. This knowledge is essential in the initial stage of the design process, and is also the basis of the rationality of the final design work. Without the preliminary design research, the design works will lose the theoretical support. This module is mainly concentrated in the junior and senior stages, and the freshman and sophomore stages are also arranged in the front. Therefore, we can consider allocating less credits in the sophomore stage, introducing the concept of design research, describing the methods and means of design research and user research in detail in the third stage, and then using the related topics of other professional core courses to strengthen the content of user research in the fourth stage.

\section{"Interdisciplinary knowledge" module}

In addition, we should set up a "cross professional knowledge" module according to the requirements of the new era for design and the existing employment situation. According to the above formula, the total credits of interdisciplinary knowledge in four years is about 8 , and the proportion is relatively high, mainly concentrated in the junior and senior stages, and also has a certain distribution in the sophomore stage. We can cultivate students' interdisciplinary knowledge system by adding interdisciplinary compulsory courses and elective courses, studio system, workshops and other auxiliary training means in the junior and senior stages. Interdisciplinary knowledge should be combined with the core competence and knowledge of product design specialty to form an organic whole, so as to be better applied to design topics and design practice. This will be completed in the follow-up study. 
Finally, through workshops, lectures, salons, quality development courses and so on, improve students' understanding of design, hands-on ability, team cooperation ability, so as to improve students' comprehensive quality, in order to make more full preparation for future employment.

\section{Summary}

This study analyzes the changes of design needs in the new era, and the new needs of these changes for design talents, so as to preliminarily determine the goal of talent training and make a preliminary study on the elements and principles of the talent training system. These studies have a very good reference value for the application-oriented local colleges to establish the talent training objectives of product design specialty, and to clarify the main ability and main knowledge of product design specialty, so as to build a specific talent training system. But this study did not give the final product design professional training system, in which the specific curriculum, extracurricular organization and other aspects need further research. In the follow-up research, I will carry out more in-depth investigations and research, and through the analysis and quantitative way, carry out a wide range of professional internal discussion, and combine with the characteristics of our school product design major and the specific situation of students, to get the specific curriculum in the training system, and in the end to build a complete training system. At the end of this study, I hope more colleagues will participate in the discussion and form a more complete result.

\section{References}

Action line of "new engineering" construction ("Tianjin University action"). (2017,December 05) Retrieved from http://www.moe.gov.cn/s78/A08/moe_745/201704/t20170412_302427.html

Hou Peiyong. (1997). Thick foundation, wide caliber, strong ability and high quality -- the target mode of cross century talent training in Colleges and universities. Science and technology, talent and market (01), 25-27

Lu Guangpu and Zhang Lu. Research on the talent training mode of product design specialty under the background of "intelligent manufacturing in China" -- Taking Local Universities as an example [J]. Education and teaching forum, 2020 (28): 37-39

Qian Feng and Zhang Jun. (2016). Innovative research on talent training mode of product design major in Local Undergraduate Colleges -- Taking product design major of Yancheng Institute of technology as an example. Design (05), 91-93

Zhang Lu. (2021). Made in China 2025_ China Academic Journal Electronic Publishing House. (4), $9-10$ 